\title{
Reasonable Reactions to the Wrongness of Rape
}

\author{
JOHNGARDNER *
}

In a bracing recent paper ${ }^{1}$ my old friend bob Watt invites me to make a 'paradigm shift'. ${ }^{2}$ He is inspired to do so by his reading of an essay that Stephen Shute and I wrote nearly two decades ago, called 'The Wrongness of Rape'. ${ }^{3}$ The world as portrayed in this essay, Watt says, 'does not accord with reality as perceived in our everyday lives by most, if not all, of us.' 4 The words 'if not all' in this sentence add something of importance. Watt hopes that the world as portrayed in our essay does not accord with reality even as Shute and I perceive it. I think he worries (with characteristic kindness) that, if we perceive reality in the way in which it is portrayed in 'The Wrongness of Rape', we are basket cases in need of therapeutic intervention.

In this response - in which I take the opportunity to revisit several themes from the original essay - I hope to reassure Watt

\footnotetext{
${ }^{\star}$ Professor of Jurisprudence, University of Oxford.

1 bob Watt, 'The Story of Rape: Wrongdoing and the Emotional Imagination', Denning Law Journal 26 (2014), 46. Hereafter Watt, 'Story'. For the uninitiated, bob writes his forename with a lower-case ' $b$ '.

2 Watt, 'Story', 46.

3 John Gardner and Stephen Shute, 'The Wrongness of Rape' in Jeremy Horder (ed), Oxford Essays in Jurisprudence: Fourth Series (Oxford 1998); reprinted with minor changes in John Gardner, Offences and Defences (Oxford 2007). Hereafter Gardner and Shute, 'Wrongness'. Page references here are to the 2007 reprint, which is used by Watt and many others.

4 Watt, 'Story', 46.
} 
(and others of like mind) that the position taken in the essay, particularly on the subject of emotions, is not the disturbing one that he reads into it. There is no reason, I will suggest, for me to 'reserve [my] analysis to [my] professional li[fe]'5. Nor do I so reserve it. The analysis we offered in 'The Wrongness of Rape' comports with my own everyday experience. For the ShuteGardner account of the wrongness of rape has quite ordinary phenomenological ramifications. Ultimately it helps to explain, rather than to explain away, the central importance of emotional experience in human life, including of course my own.

I

Watt thinks that Shute and I underestimate the importance of emotions in moral experience, and, more generally, in human life. We make 'a mere sideshow' of them, he says. ${ }^{6}$ To bear this claim out he latches onto the technical word 'epiphenomenon', ${ }^{7}$ which Shute and I used several times in our essay. ${ }^{8}$ In the crucial sentence, to which our repetitions of the word are implicitly referring, we claimed that 'emotional reactions [to rape] ... must be epiphenomenal, in the sense that they cannot constitute, but must shadow, the basic, or essential, wrongness of rape.' 9 This sentence does not say what Watt reads it to say, namely that emotional reactions to rape can only play a minor or peripheral role in determining the wrongness of rape. It says that emotional reactions to rape can only play a derivative role in determining the wrongness of rape. A derivative role in the relevant sense might well be a major role, even the dominant role.

5 Watt, 'Story', 46.

6 Watt, 'Story', 49.

7 Watt, 'Story', 46, 47, 49, 50, 59, 60.

8 Gardner and Shute, 'Wrongness', 6, 7, 21.

${ }^{9}$ Gardner and Shute, 'Wrongness', 7. 
Consider an example from a very different context. I have chosen the example to bring out that the Shute-Gardner argument is not specifically about emotional reactions, but about reactions more generally. The most weighty reason to keep a promise, and the one that lends most force to one's duty to do so, is often the fact that the promisee relied on it. Why would she have relied on it? Well, it was a promise, and a promise is (barring special circumstances) binding on the promisor, and thus fit to be relied upon. So far so good. But the promisee's reliance cannot now be used to explain why the promise is binding. If the fact that a promise is anyway binding is what makes it fit to be relied upon, the fact that the promise is relied upon cannot also be what makes it binding. The reliance reason for keeping it now points back to some other reason for keeping it. This reason (whatever it is) is the 'basic or essential' reason, the one that holds us to our promises even when there is no reliance, and hence helps to justify reliance when there is reliance. Notice, however, that this basic or essential reason may have rather little force on its own. One's duty to keep a promise may not be very stringent until the reliance comes along. Still the reliance remains the derivative consideration; it builds on the more basic one. ${ }^{10}$

Shute and I thought that much the same points could be made in connection with strong feelings about rape, including but not limited to the strong feelings of those who are raped. If the strong feelings in question are reasonable ones (as we both thought they generally are) there must be something else wrong with rape, some more 'basic or essential' wrong-making feature

${ }^{10}$ For recent discussion of this issue in the context of promising (with greater subtlety than the present context allows) see David Owens, 'The Possibility of Consent' Ratio 24 (2011) 402 and Joseph Raz, 'Is There a Reason to Keep a Promise? in Gregory Klass, George Letsas, and Prince Saprai, Philosophical Foundations of Contract Law (Oxford 2014). 
of rape, that makes the strong feelings reasonable. Possibly the 'basic or essential' feature doesn't make rape very wrong by itself. Possibly the grief or shame or horror or rage of the victim (and possibly, in some cases, the anxiety or apprehension of other potential victims, the pity or sorrow or guilt of friends and family, etc.) is what makes the biggest difference to the wrongness of rape. So possibly it is the trauma of rape - let's use this as our umbrella word - that should most concern us in the end. But that doesn't in any way neutralize our interest in finding what else it is about rape that makes for such trauma. For we should think of the victims of rape as people like ourselves, capable of evaluating their own reactions and (perhaps only with therapeutic help) eventually getting them in some kind of perspective and proportion. Shute and I regarded the possibility of relating to one's emotions in this way as a matter of very great importance, not just for theorists like ourselves who are interested in the emotions as a subject of study, but also for the survivors of rape. Rape, we thought, is dehumanizing enough already without those who have been raped being condescendingly regarded as having lost their human sensitivity to value, their ability to interpret what has happened, to see how it matters, and to relate critically to their own reactions to it (as well as to the reactions of others). The idea that rape survivors can only be passive in the face of their own pain, overwhelmed and trapped by senseless feelings, only adds insult to injury.

Shute and I devised a hypothetical, now widely-discussed in the literature, to help us work out what it is about rape that is basically or essentially wrong, something that could explain why strong feelings about it are in order. The rape in the hypothetical (heavily sleeping victim, no ill-effects, rape never comes to her or anyone else's attention, rapist coincidentally killed just after 
leaving) was structured to leave no trauma behind it, except for the traumatized reactions of our readers. ${ }^{11}$ The latter exception is highly significant, although we deliberately did not mention it at the time. We wanted the imaginary rape in our essay to stir up strong feelings in our readers even though (by hypothesis) there could be no feelings at all about the rape on the part of anyone inside the imaginary world in which it happened, for in that world (by hypothesis) the rape went entirely undetected.

In this ambition of stirring up emotion in our readers we succeeded beyond our dreams. Watt is just the latest in a long line of readers to react to our scenario with 'disgust ... outrage ... an inward shudder for the victim.' ${ }^{\prime 2}$ Indeed that was how we reacted to the example ourselves. Why did we look for the same reaction in others? We wanted to test whether the relative moral importance of trauma in rape cases is similar to - for example the relative moral importance of reliance in promise cases. In promise cases, it is plausible to think that reliance is what tends to make the biggest difference to the stringency of the duty to keep the promise. It is plausible to think that it is not very important to keep a promise that is never relied upon by anyone - say, because it is promptly forgotten by everyone. Is the same true of a rape that goes undetected? Our experiment suggested that, for most people, it is not. And Watt is one of the guinea-pigs who has helped to confirm that result. He has helped to confirm our hunch (reflected in our own feelings about the case we invented) that an undetected rape, hence a rape giving rise to no trauma, is still very seriously wrong. Would Watt want to say that the rape in our scenario is wrong but not very seriously wrong, something like breaking a promise that nobody recalls or telling a lie that nobody hears? Clearly not. Like us, he is outraged by the rape. In which case, he helps to vindicate the approach of our essay.

11 Gardner and Shute, 'Wrongness',

12 Watt, 'Story', 49. 
There is something seriously wrong with a rape even when, by hypothesis, it gives rise to no trauma. What is that something? That was precisely our question, and it has not gone away.

Watt could not be further from the truth, then, when he says that our 'readers are implicitly required to step inside [the] analysis and to abandon the normal human responses felt when a person is confronted with a story of rape. ${ }^{13}$ Such abandonment by our readers would have defeated part of the object of the exercise. ${ }^{14}$ We needed plenty of serious reader-outrage in order to test our hunch that rape with no bad consequences, including no trauma, is still wrong in a very serious way, such that one should still be seriously outraged on being told of it. And still seriously outraged, notice, even when it is identified in advance as an imaginary scenario and presented in an emotionally-flat 'analytical philosophy' tone. ${ }^{15}$ Nobody feels this pained - do they? - if we test them with imaginary cases of inconsequential promise-breaking, inconsequential lying, or inconsequential theft. To warrant such outrage whatever is 'basically or essentially' wrong with rape must be something towards the more outrageous end of the spectrum. While the trauma felt by

\footnotetext{
13 Watt, 'Story', 49.

${ }^{14}$ A more apt target for Watt's quoted criticism would be Pedro Almadóvar's film Talk to Her (2002) in which a scenario akin to the one Shute and I devised is embellished, almost romanticized, in such a way as to make the viewer 'abandon the normal human responses felt when ... confronted with a story of rape.' Almadóvar's experiment differed from ours. He really did want his audience to 'step inside his analysis' - only to be disturbed, as he escorted them back out, at how easily he had made them complicit or quiescent.

15 Although our tone could itself be the object of added outrage. We pointed that out in the essay (Gardner and Shute, 'Wrongness', 2), hoping that our readers would not allow their outrage at the thought of the imaginary rape to get mixed up with their outrage at our writing about it with such sang-froid as we did. To judge by Watt's reactions, our hope was in vain. Some of his complaints seem to be complaints about the dessicated ways of philosophers as such. See e.g. Watt, 'Story', 49.
} 
survivors may still be a major factor in assessing the seriousness of particular rapes - we left that contentious matter open ${ }^{16}-$ the underlying outrageousness of rape, the very thing that Shute and I were trying to discover, clearly can't be something slight.

By charging that Shute and I make 'a mere sideshow' of the emotions, Watt means that we underestimate their importance. But not only that. He also means that we err in treating emotions as answerable to reasons. If that is an error, I have just repeated it in sections I and II. I treated it as a proper question to ask whether a certain emotion experienced by a rape victim (or by anyone) is reasonable, in proportion, sensitive to value, etc. Watt denounces this (as he sees it) 'Kantian' rational scrutiny of our emotions in favour of (what he takes to be) its 'Humean' rival, according to which 'reason is the slave of the quiet passions. ${ }^{\text {' }}$ ' For Watt this means 'that our first evaluation of an occurrence, such as rape, is emotional rather than rational,' 18 that 'emotions are right at the forefront of our assessment of wrongdoing. ${ }^{19}$ In this sense, '[o]ne might even say that reason is the true epiphenomenon. ${ }^{\prime 20}$

16 Contentious because for some 'rape is rape' and does not admit of degrees of seriousness. This means refusing to differentiate among rapes according to their consequences, and hence rejecting 'victim impact statements' and the like. 'Rape is rape' is a slogan usually traced to 1970s campaigner Del Martin. She continued: 'The identity of the rapist does not alter the fact of his act, nor lessen its traumatic effects on the victim.' Del Martin, Battered Wives (Volcano, California 1976), 181, italics added. Notice that the italicized words allow that rape would be less serious if it were less traumatic. So Martin did not believe that rape did not admit of degrees of seriousness. She merely thought that the identity of the rapist, on its own, was irrelevant to the degree of seriousness.

17 Watt, 'Story', 58.

18 Watt, 'Story', 59.

19 Watt, 'Story', 60.

20 Watt, 'Story', 59. 
Consider Watt's words 'our first evaluation of an occurrence, such as rape, is emotional rather than rational.' Clearly the word 'first' here is a red herring. There was nothing in what Shute and I wrote to suggest that one feels or should feel no horror, grief, fury or dread at anything in advance of knowing what it is about that thing that makes it horrifying, grievous, infuriating or dreadful. Indeed what we said is even compatible with the more radical possibility that horror, grief, fury or dread may properly strike one even before one knows what the horrifying, grievous, infuriating or dreadful thing is (never mind knowing what it is about it that makes it horrifying, grievous, infuriating or dreadful). Watt misleads his readers, then, by presenting his disagreement with us as being about whether, when we face something that (properly) evokes emotion, emotion is (properly) the first thing to be evoked. Probably this is just a slip on his part; probably it is an explanatory rather than a temporal primacy that he really has in mind when he puts emotions 'first'.

More revealing, however, are the remaining words in Watt's sentence. In acknowledging that 'our ... evaluation of an occurrence' can be emotional, he acknowledges that emotions can have objects, that it is possible to feel horror, grief, fury, or dread at something or about something or towards something, including something 'such as rape'. Not only possible, one might add, but par for the course. Even if one does not yet know what the object of one's emotional reaction is (even if one does not yet know what it is, say, that is giving one the creeps or the screaming heeby-jeebies) it is surely a built-in feature of one's emotional reaction that it draws one's attention to its object, or at least puts one on the lookout for its (as yet undetected) object. If one doesn't yet know what one is reacting to, one's reaction inclines one to wonder what it is that one is reacting to.

If that much is true, then already one is relating to one's own reactions in the 'critical' way that I described in section III above. One is asking why - in response to what - one feels as one does, and so one is treating one's emotions as answerable to reasons. If 
one discovers that there is nothing to be afraid of, or nothing to be angry about, or nothing to be surprised at, then typically one's fear or anger or surprise (as the case may be) evaporates although of course it may give way to embarrassment at one's gullibility, or shame at one's prejudice, etc. And if one discovers that what there is to be afraid of or angry about or surprised at is not as much as at first one imagined, then typically one's fear or anger or surprise abates pro tanto - although of course it may give way to annoyance at one's tendency to exaggerate, frustration at one's lack of discernment, etc. The necessary adjustments when one discovers the truth in such cases might not, I hasten to add, be instantaneous; emotions that we discover to be misplaced, misdirected, or out of proportion, can be sticky. Sometimes one even hunts around subconsciously to find some alternative object that would license one to continue feeling as one already does. One's emotion cries out, if you like, for some object in the world to which it may still qualify as a fitting reaction. And that is all that there is to (typical) emotion's answerability to reasons. It is no more and no less than is already implicit in Watt's own proposal that in or by an emotion we 'evaluat[e] ... an occurrence'. We take something good or bad in the world to befit the emotion in question, even if we don't yet know what that something is. And Watt says precisely that, even about rape: at the thought of rape, we suffer 'natural emotional nausea'. ${ }^{21}$ Not any old reaction, notice, but the one that befits rape, and that comes naturally to us as beings who respond to reasons.

Does Watt manage to distance himself somehow from the implications of his remarks, as I have just exposed them? Elsewhere in his discussion he is sympathetic to a view put forward by John Stanton-Ife, to which I am also sympathetic,

21 Watt, 'Story', 61. 
that rape is or is prone to be 'destructive of personality itself..$^{22}$ That of course is a reason too, a reason, if Stanton-Ife is right, that is capable of bearing dramatically on the wrongness of rape. When it bears on the wrongness of rape, it bears by the very same token on the reasonableness of various emotional reactions to rape. That a victim's personality would or might be destroyed by rape (if and when that is true) is surely a major reason to fear being raped, as well as to abhor rapists and relish their getting their comeuppance, to be saddened by the human capacity for evil, to be anxious or alarmed for the victim, to feel vengeful or heartbroken on her behalf, and more generally, in a suitably empathetic way, ${ }^{23}$ to share the victim's pain.

These emotional reactions all answer to (inter alia) the Stanton-Ife reason, when that reason holds. But you may say and Watt may be read as saying ${ }^{24}$ - that the last entry on the list reveals a special twist in the Stanton-Ife reason. For one part of a victim's personality that might be damaged or destroyed by rape is the emotional part, which is, as Watt rightly says, a 'vital part'. ${ }^{25}$ The person raped might be thereby rendered unrecognizable in respect of some emotional traits (going from sunny, open, and carefree, say, to wary, preoccupied, and panicky). Couldn't this help to show that reasons are the 'true epiphenomenon' in the case of rape? We should all have negative emotional reactions to rape partly for the Stanton-Ife reason, true

22 Watt, 'Story', 60, referring to John Stanton-Ife, 'Horrific Crimes' in R.A. Duff et al (eds), The Boundaries of the Criminal Law (2010). Watt's sympathy for the view is conveyed in Watt, 'Story', $47 \mathrm{n} 3$.

${ }^{23}$ I believe I am at one with Watt in saying that empathy is not an emotion; it is an ability and propensity to share in another's emotions, also called 'fellowfeeling.' I would add, as maybe Watt would not, that empathetic people tend to draw the line at unreasonable feelings. Empathy is not a judgment-free trait. For discussion see Jesse Prinz, 'Against Empathy' Southern Journal of Philosophy 49 (2011), 214, and the reply in the same volume by Julia Driver.

24 Watt, 'Story', 47n3.

25 Watt, 'Story', 49. 
enough; but the Stanton-Ife reason itself refers us back to (the rape victim's) emotions. So this explanation of rape's wrongness bottoms out, does it not, in emotions rather than reasons? Not so if the emotions have the rape as their object. Not so if Watt is right to think that, in or by her emotions (however transformed by the rape) the rape victim 'evaluates' the rape. Not so, in other words, if she is still capable of asking what it is about the rape that makes her feel as she does. Suppose, as is understandable, that at least in the early months she finds it hard to grasp the reasons why she feels as she does (perhaps because it is hard to confront them when the experience is still so immediate). Finding the reasons hard to grasp, but still tortured by her feelings, she sometimes worries that she might be going mad. That worry is fully intelligible on the Shute/Gardner view, which turns out also to be the Watt view: since even very intense emotions answer to reason, being unable to grasp the reason for them is worrying. So one reassuring sign concerning our rape victim's mental health is that, when confronted with very sticky emotions that she struggles to make intelligible even to herself, she still has this fully intelligible worry about her sanity. That shows that there is hope for her to get back to living her life, even if that means living a different life from the one she lived before and would have been living still, were it not for the rape. ${ }^{26}$

\footnotetext{
${ }^{26}$ Is having a different life necessarily a bad thing? You might think not in a case in which the life afterwards includes less naivety, more strength of character, more sense of who one's friends really are, etc. But I tend to think that even a case like this is double-edged. Disillusionment represents a harm, it seems to me, even if one should not have had the illusions in the first place. I say more about this in my forthcoming book From Personal Life to Private Law.
} 
Since Watt seems to hold emotions answerable to reasons in exactly the same way that Shute and I do, one must conclude that he mistakenly takes us to be holding emotions answerable to reasons in some other, presumably more objectionable, way.

What is that way? Strangely, without supporting evidence, Watt seems to land us with the view that people should react to the world dispassionately, repressing their emotions in favour of 'reason[ing] out a course of action' in a cool-headed way. ${ }^{27}$ This is a view commonly (although contentiously) associated with Kant, and according to Watt 'the thrust of [the Shute-Gardner] argument is Kantian.'28 Whether it is Kant's view or not, however, it is diametrically opposed to our view. Since emotions answer to reason, they belong to what Aristotelians (among whom we number ourselves) call 'the rational part of the soul'. ${ }^{29}$ True, one's emotions are capable of seducing one into doing the wrong thing; but reasoning out a course of action in a coolheaded way is no less capable of doing that. Neither the passionate nor the dispassionate among us has any a priori claim to be generally more effective in securing anyone's (including their own) conformity with reasons; whether a more or less emotional reaction will lead to better reason-conformity just depends on which reasons we are talking about, which emotions, in which circumstances, for which person, in respect of which action, and so on. Sometimes, surely, a cold calculation is just the opposite of what is called for. Sometimes fleeing in terror, looking away in disgust, remonstrating furiously, weeping with frustration, or hanging one's head in shame is the only reasonable reaction. Shute and I said nothing to suggest otherwise.

27 Watt, 'Story', 59.

28 Watt, 'Story', 47.

29 See e.g. Martha Nussbaum, 'Aristotle on Emotions and Rational Persuasion’ in A.O. Rorty (ed), Essays on Aristotle’s Rhetoric (Berkeley 1996). 
In fact, and somewhat strangely, it is Watt who suggests otherwise. Watt ultimately joins with Kant, or with Kant as contentiously interpreted, in asserting the irrationality of emotion'. ${ }^{30} \mathrm{He}$ thereby gives succour to the false idea that emotion tends to stand in the way of conformity with reasons, and should, so far as conformity with reasons is concerned, be avoided. It follows from this idea that if emotions are to be 'rehabilitated', ${ }^{31}$ to be restored to their proper place as 'a vital part of the human personality' 32 as Watt thinks they should be, that rehabilitation cannot be in the name of conformity with reasons. Accordingly, thinks Watt, we had better learn to care less about conformity with reasons. Why be reasonable, he wonders, when you could be in touch with your feelings? And he imagines us responding, tit-for-tat, with the reverse question: Why be in touch with your feelings when you could be reasonable? That question certainly has something going for it as compared with Watt's. Both questions are 'why?' questions that can only be answered by giving a reason. Thus Watt's question 'why be reasonable when you could be in touch with your feelings?' is a question the asking of which already presupposes the primacy of reasonableness. ${ }^{33}$ That gives a huge advantage to the riposte: Why be in touch with your feelings, when you could be reasonable? But be that as it may, the riposte question is not the one that Shute and I asked. Our question was: How about having, or at least aspiring to have, reasonable feelings? We therefore did not sign up, as Watt does, to the false choice between reasonableness and emotionality. For we did not share his faith in the 'irrationality of emotion'. We thought (and I for one continue to think) that emotions not only answer to reasons,

30 Watt, 'Story', 61.

31 Watt, 'Story', 49.

32 Watt, 'Story', 49.

33 Gardner, 'The Mark of Responsibility', Oxford Journal of Legal Studies 23 (2003), 157; later version in Gardner, Offences and Defences, above note 3. 
but often answer to reasons well, helping (sometimes enabling) people to do and be what they have reason to do and be.

The last formulation shows how Watt can square his belief in the 'irrationality of emotion' with the belief that he seems to share with Shute and me, namely that emotions answer to reasons. Obviously it is possible to hold that emotions answer to reasons while holding that they do so badly - that, when it comes to improving our conformity with reasons, emotion is generally a poor guide, or at any rate a poorer guide than dispassionately 'reason[ing] out a course of action'. This is a popular combination of views - emotions are not arational, but they are irrational - and it is plausible to attribute it to Kant. Curiously, it is also plausible, on closer inspection, to attribute it to Watt. But it is not at all plausible to attribute it to Shute and me. We say of emotions: they are not arational and they are not notably irrational either. Allowing oneself to be guided by one's emotions can sometimes lead one astray, of course. ${ }^{34}$ But cool calculation is no less prone to do so, at any rate a priori. (There may of course be a posteriori discrepancies in the success rates of these two modalities across different classes of actions, different agents, different reasons, different emotions, different times and places, etc. All of that would call for empirical research.)

V

A different strand of Watt's critique is concerned, not with the very idea that emotions answer to reasons, but with the particular reason that Shute and I advanced as bearing on the wrongness of rape, and as providing a basis for negative emotional reactions to it. Rape, we suggested, is the 'sheer use' of a person. ${ }^{35}$ This is the

${ }^{34}$ On overestimating the rational reliability of emotion, see my, 'Wrongdoing by Results: Moore's Experiential Argument', Legal Theory 18 (2012), 459.

${ }^{35}$ Gardner and Shute, 'Wrongness', 16. 
'basic and essential' reason (a) not to commit it and (b) to feel as we do feel about it when it is committed. In this proposal Shute and I admittedly alighted on a vaguely Kantian idea. ${ }^{36}$ Perhaps it is this that leads Watt to think, mistakenly, that we must follow Kant on other matters too. Be that as it may, I am no longer as sure as I once was that the proposal that Shute and I made is exactly right. All I can say is that it is in the right neighbourhood. I think we were right to think of rape as a kind of objectification of a person, but possibly wrong to narrow down the relevant kind of objectification so exclusively to sheer use. ${ }^{37}$

Watt does not, however, make an objection to our proposal along these lines. He does not say that some rapes are not sheer uses. Rather he repeats a converse objection made by Danny Statman a few years ago: ${ }^{38}$ that many sheer uses are not rapes. Statman gave the example of 'a medical student making use of a person's body by creeping into her room whilst she is unconscious and examining her facial structure to revise for his examination.' ${ }^{39} \mathrm{He}$ didn't deny that this would be wrong; he merely pointed out that what Shute and I said about rape would be 'incomplete' 40 if we failed to explain why the rape, in our much discussed example, seems so much more egregious than the facial examination in his example, even though both are sheer uses of a person. Watt does not mention my reply to Statman, in which I pointed out that Shute and I had, in fact, offered the sketch of an explanation towards the end of our

36 We said that we 'echoed' Kant: Gardner and Shute, 'Wrongness', 17.

37 I was given fresh food for thought on this question by Mari Mikkola, 'Dehumanization' in Thom Brooks (ed), New Waves in Ethics (Basingstoke 2011) and more recently by Michael Plaxton, 'Nussbaum on Sexual Instrumentalization', Criminal Law and Philosophy 10 (2016), forthcoming.

38 Daniel Statman, 'Gardner on the Wrongness of Rape', Jerusalem Review of Legal Studies 4 (2012), 105. Hereafter Statman, 'Gardner'.

39 Watt, 'Story', 47, paraphrasing Statman, 'Gardner', 108-9.

40 Watt, 'Story', 47, echoing Statman, 'Gardner', 109. 
essay. ${ }^{41}$ Our explanation was that rape takes an important and socially influential ideal of subject-subject relations - human sexual relations - and turns it on its head. This gives a special social meaning to rape that other sheer uses do not share. ${ }^{42}$ In a new (forthcoming) article, called 'The Opposite of Rape', I have explored this point in a lot more detail. ${ }^{43}$ I have worked out the relevant ideal of good sex in a way that reveals, I think, why rape is the very antithesis of it, and thereby helps us to see what it is that is especially wrong with rape that does not extend to Statman's example of the facial examination. You do not need to read 'The Opposite of Rape', however, to see that Shute and I anticipated Statman's point and answered it. In my reply to Statman I even quoted the relevant paragraph. ${ }^{44}$

Watt turns the screw a little further than Statman. He devises an example of sheer use of another person in human sexual relations that does not strike him as wrong at all, and certainly nowhere near the rape end of the spectrum. This move, if successful, neatly sidesteps what Shute and I said in anticipation of Statman's objection. For we played the 'sex is special' card to show what is especially wrong with sheer use of a person in the sexual context; and Watt's example is designed to show that sheer use of a person need not be especially wrong even in the sexual context. In Watt's example, a woman called Mary 'wants to be "used" in a controlled sense by [her lover, John] so that she feels no responsibility for that which has happened.' 45 In particular (in a nice echo of the rape hypothetical that Shute and I devised) Mary would like to experiment with John's attempting

41 Gardner, 'In Defence of Offences and Defences', Jerusalem Review of Legal Studies 4 (2012), 110.

42 Gardner and Shute, 'Wrongness', 22-3.

43 Gardner, 'The Opposite of Rape', draft online at http://bit.ly/1Ph522i.

44 Gardner, 'In Defence of Offences and Defences, above note 41, at 126-7.

45 Watt, 'Story', 54. 
to 'make love to her while she is asleep.' 46 What could Shute and I say about this case to explain how distant it is from our case, without giving up our 'sheer use' doctrine? A possible response is that Watt's is an example of 'sheer use' in quotation marks, rather than sheer use. In an aspect of the story that Watt only hints at, and may not mean to rely upon, Mary's wish to experiment in this way is an aspect of what is sometimes known as a 'rape fantasy'. ${ }^{47}$ If Watt means to rely upon this feature of the example, then the example tends to count in favour of, not against, the position that Shute and I took. For if rape is sheer use of a person, then a theatrical representation of rape ought by the same token to be a theatrical representation of sheer use of a person. On this reading, Watt's words 'controlled in a sense' mean that John is to be guided throughout by Mary's script. He must regard and conduct himself as a player in Mary's production, not engaging in sheer use of her but only in the portrayal of sheer use of her, albeit as authentically and with as much improvisation as he can manage and she requires. Imagine that he gets carried away with the role and starts to regard the sleeping Mary as his sex toy rather than as the impresario behind the show in which she plays the role of his sex toy. Then, surely, the case shifts decisively back towards our rape hypothetical.

But suppose the 'rape fantasy' theme is another red herring in Watt's critique. Suppose Mary doesn't want any masquerade. She wants her lover to fuck her while she's out cold, 'just like the imaginary woman in that Shute-Gardner article I was reading today' (she tells him). The whole point is that she's volunteering to be an actual sex toy. Tonight, after she's popped a couple of roofies and got herself a bit aroused, John is to use her in her stupefied form as if she were a kind of super-realistic inflatable doll. No injuries allowed of course (remember the Shute-

46 Watt, 'Story', 53.

47 Watt, 'Story', 54n27. 
Gardner example) but otherwise it's all to be at his whim, with no thought of her as any kind of participant. The thought that she will be reduced to an object in this way turns her on, she says, and the thought of once having been reduced to an object in this way, she thinks and says, will routinely turn her on afterwards. 'Why not?' she asks. 'It's just some harmless fun.' If that is more or less the story, then Watt's example fits into a different part of the Shute-Gardner analysis. ${ }^{48}$ It is the kind of sexual activity which is covered by the right to sexual freedom. People may waive the duty that others owe them not to mistreat them sexually. It does not mean that there is no mistreatment. Like other rights to freedom (freedom of speech, association, conscience, etc.), the right to sexual freedom is mainly there to license people to do objectionable things, and often these things remain objectionable even when done under the license of the right. The right to sexual freedom licenses people - mainly by use of their power to consent - to carry out ignominious sexual experiments with others, to take up sexually degrading lines of work, and of course to have casual and meaningless 'utility sex' with virtual strangers. Exercising the right, as Mary does with John, is capable of taking acts in the 'sheer use' category right out of the 'rape' category even though they meet the other conditions to qualify as rape. To test the hypothesis, just imagine that John is really into Mary's idea, not out of an uxorious zeal to cater to her peculiar tastes, but because he really likes the idea of fucking an unconscious woman. That doesn't make him a rapist but it does make him a sleazeball with what today are sometimes called 'rapey' tastes, and it's just as well for him that he has met someone, in Mary, who happens to exercise her right to sexual freedom in a way that caters, depressingly, to his sleaziness. Why, perhaps his sleaziness is eveb part of his attraction for her. As Watt says, many people have kinky sexual tastes, including tastes

48 Gardner and Shute, 'Wrongness', 16-21. 
to use others and be used by them, and many suffer associated sexual attractions for what their parents might call 'unsuitable' partners. ${ }^{49}$ The right to sexual freedom, as Shute and I explained at some length in our essay, is what protects people in giving effect to those tastes and attractions even where, as Watt very understatedly puts it in Mary's and John's case, 'we may not wholly approve of the[ir] antics. 50

So it turns out that Shute and I anticipated Watt's example as well as Statman's. We explained when and why sheer use of someone in sexual relations is 'not wrongful'51 (Watt's expression) even when it meets all the other conditions for qualifying as rape. On the other hand we did not suggest, as Watt thinks we should have done, that it is 'it is the emotional context of that "use" which is important." 52 Nor should that be conceded. I do not doubt that in sexual matters, emotional connection is of great importance. It is one of many respects in which good sex may be good. It can be a redeeming feature of sex that it is some other ways pretty bad. But I very much doubt whether it has any role to play in explaining why John, while (zealously or otherwise) carrying out Mary's kinky request, is no rapist. Possibly it explains, further back, why Mary felt comfortable in giving John her consent to make sheer use of her. But it is her consent that matters to the question of why he is no rapist, and that would equally protect him from being a rapist if Mary were an easygoing stranger he met in a bar, or a niche prostitute who specializes in offering the use of her sedated body to sleazy men who are into the idea of fucking an unconscious woman. The emotional context of all this sexual activity is a matter of evaluative importance in various ways. But it is not

49 Watt, 'Story', 58.

50 Watt, 'Story', 58.

51 Watt, 'Story', 54.

52 Watt, 'Story', 55. 
important, I persist in thinking, in explaining what qualifies as rape, or what is basically and essentially wrong with rape. 